\title{
Disease Mapping of Pertussis in Malaysia
}

\author{
Zakiyah Zain ${ }^{1,2,}$, Nazrina Aziz ${ }^{1,2}$, Lim Jia Qian', Goi Jia Shun ${ }^{1}$ \\ ${ }^{1}$ Department of Mathematics \& Statistics, School of Quantitative Sciences, Universiti Utara Malaysia, 06010 UUM Sintok, Kedah, \\ Malaysia \\ ${ }^{2}$ Institute of Strategic Industrial Decision Modelling (ISIDM), Universiti Utara Malaysia, 06010 UUM Sintok, Kedah, Malaysia
}

Received November 18, 2020; Revised June 1, 2021; Accepted June 21, 2021

\section{Cite This Paper in the following Citation Styles}

(a): [1] Zakiyah Zain, Nazrina Aziz, Lim Jia Qian, Goi Jia Shun, "Disease Mapping of Pertussis in Malaysia," Universal Journal of Public Health, Vol. 9, No. 4, pp. 188 - 193, 2021. DOI: 10.13189/ujph.2021.090404.

(b): Zakiyah Zain, Nazrina Aziz, Lim Jia Qian, Goi Jia Shun (2021). Disease Mapping of Pertussis in Malaysia. Universal Journal of Public Health, 9(4), 188 - 193. DOI: 10.13189/ujph.2021.090404.

Copyright $\odot 2021$ by authors, all rights reserved. Authors agree that this article remains permanently open access under the terms of the Creative Commons Attribution License 4.0 International License

\begin{abstract}
The pertussis disease, which is termed as the "100-day cough", the incidences of which has dramatically increased over the years. This article reports the number of pertussis patients in all of the states in Malaysia from the year 2011 to the year 2018 and relative risk estimation for all of the states in 2018. Disease mapping is used in this article to visualize the risk area in Malaysia. The relative risk for every state in Malaysia is estimated using the standardized morbidity ratio (SMR) and a disease map is created using the ARCGIS software to demonstrate the relative risk of pertussis disease for every state more clearly. From the result, Johor is shown to be the lowest-risk area while Terengganu and Kedah are shown to be the highest-risk areas of the pertussis disease. Based on the map, the implementation of actions for controlling the disease is needed for the areas with very high risk of pertussis disease.
\end{abstract}

Keywords Pertussis, Disease Mapping, Standardized Morbidity Ratio, Relative Risk Estimation, 100-Day Cough

\section{Introduction}

Pertussis is an extremely contagious respiratory disease that is termed as the "whooping cough" or "100-day cough". Pertussis causes 20 million cases worldwide, 90\% of which happen in developing countries [1]. The most serious cases and deaths often occur in infants, although pertussis can happen at any age [2]. Pertussis is an airborne disease, which means it spreads through droplets that harbour bacteria called Bordetella pertussis in the breath of the infected person. When an infected person coughs or sneezes, others might inhale infectious bacteria and become infected with pertussis. People who are infected with pertussis may cough so hard that it leads to vomiting, broken ribs or exhaustion. Repeated vomiting might cause diseases such as pneumonia, encephalitis and malnutrition. Infants suffering from pertussis often face breathing difficulties and may not breathe for some time. The pertussis disease progresses in 3 distinct phases: catarrhal, paroxysmal and convalescent. In the first phase, the infected person develops symptoms of a common cold such as sneezing. The next stage is characterized by intense coughing for a very long duration, lasting from 1 to 10 weeks. In the final stage - convalescent, often there is lesser sudden uncontrollable coughing, but this can last for weeks or even months [3].

Pertussis was first reported in the Middle Ages, and its vaccine was invented in 1914. Later in the 1940s, the pertussis vaccine was combined with tetanus vaccine and diphtheria toxoids vaccine and became known as DTP (diphtheria, pertussis, and tetanus) vaccine and became widely available. The availability of it to public has brought down the number of pertussis incidence, which is claimed to be $80 \%$ effective in preventing serious illness and death. Nevertheless, the vaccine only protects for about 5-10 years upon the complete series of vaccination. In the quest for a better vaccine, a new type of vaccine was introduced in 1990s, but a similar issue of limited protection was later discovered. Today, both vaccines are being used throughout the world with improved strategies of age-specific boosters [4].

On a global scale, the World Health Organization 
(WHO) informed 151,074 pertussis patients in 2018. About 89,000 deaths worldwide due to pertussis was estimated by WHO based on 2008 data. Later, based on 2014 data, new estimates were reported as 24.1 million pertussis patients and 160,700 deaths, mostly in children younger than 5 years worldwide. Individual country statistics of pertussis depend on the availability of the vaccine to their citizens. Despite having a high coverage of vaccination over the decades, pertussis continues as one of the main causes of deaths for vaccine-preventable diseases (VPD) worldwide. Majority of death cases involve unvaccinated infants or babies who have not completed the whole vaccination course [5].

In Malaysia, the incidence of pertussis was reported as less than one per 100,000 persons before year 2012, with zero deaths from early 2000 [6]. However, two deaths were recorded in 2012, resulting in a mortality rate of 0.01 per 100,000 persons that is 10 deaths in a million. In terms of national coverage of DTP vaccination achieved $93.6 \%$ and $97.3 \%$ respectively for the first and third doses. Recently, there have been some anti-vaccine issues in Malaysia, especially towards newborn child vaccination which may lead to an increase in the risk of infection with the disease. The anti-vaccine community believes that vaccines do not give immunity to humans but rather that the immune system provides its own immunity [7]. They also think that vaccines that contain porcine DNA may harm the body instead of bringing protection [8]. By raising awareness of this disease to the public, people may understand more about the importance of vaccines for preventing pertussis, especially towards infants.

Reporting the disease statistics is one way to increase public awareness, but what is reported and what it means are important for lasting effectiveness of the health message. In Malaysia, the conventional approach based on the total number of cases per region still persists, although the Ministry of Health has been reporting rates per specified population (e.g. 1,000 or 100,000) [9]. The former method only shows a general information for the entire region with no breakdown of details concerning the population density of the areas. This may be easily misleading as an area with higher population is more likely to record a larger number of the disease in comparison to an area with smaller population. In order to monitor and strategize efforts for disease control and prevention, it is desired to consider the population size, which can be used to compute the chances of individual getting the disease.

According to Samat and Percy [10], disease mapping technique is worth considering in monitoring and controlling a disease. It offers a clear visual of assessed risks to the geographical areas - often the darkest shade indicates the highest risk. Some recent literature on disease mapping of various diseases such as dengue [11] and cancer [12] have proven useful. A review on the utilize of geographic information systems (GIS) in use as public health tool is available [13]. However, a good map relies on the accuracy of estimation method such as relative risk, which is actively being studied due to its importance when geographical areas are concerned [14]. In this study, standardized morbidity ratio (SMR) method [15] is employed to evaluate the relative risk for each state, and a pertussis disease map is generated for the states of Malaysia.This map can be used to investigate high-risk states and thus assist government agencies with strategic planning such as resource allocation for the prioritized areas.

\section{Methodology}

Disease mapping is a common way to visualise complex geographical data which can provide a quick overview. The standardized morbidity ratio (SMR) is one of the most popular methods utilized to evaluate the relative risk for the construction of disease mapping. The SMR is a ratio obtained between the observed deaths in a population and the expected number of deaths in the same population studied. It is computed as:

$$
\theta_{i}=\frac{O_{\mathrm{i}}}{E_{\mathrm{i}}},
$$

where $O_{i}$ is the observed number of deaths or incident cases of disease in a state and $E_{i}$ is the number of cases to be expected. It is to be noted that instead of deaths, any other events of interest can be investigated in the same manner using the formula.

Suppose that the geographical area being studied is divided into $M$ mutually exclusive states $(i=1,2,3, \ldots$, $M$ ), each of the $M$ states has its observed number of cases $O_{i}$ and the expected number of cases $E_{i}$ in each state. Hence, the relative risk $\theta_{i}$ for state $i$ can be estimated by applying SMR:

$$
r_{i}=\theta=\frac{O_{\mathrm{i}}}{E_{\mathrm{i}}}
$$

The expected value could be calculated using a particular formula as shown below for the study region. The expected number of cases for this research, $E_{i}$ is calculated as

$$
E_{i}=N_{\mathrm{i}} \frac{\sum O_{\mathrm{i}}}{\sum N_{j}},
$$

where $N_{i}$ is the population of state $i$ and the summation is for $j=1,2,3, \ldots, M$. Thus, Equation (2) can be rewritten as:

$$
r_{i}=\frac{O_{\mathrm{i}}}{N_{\mathrm{i}} \frac{\sum O_{\mathrm{i}}}{\sum N_{j}}}=\frac{\left(\frac{O_{\mathrm{i}}}{N_{\mathrm{i}}}\right)}{\left(\frac{\sum O_{\mathrm{i}}}{\sum N_{j}}\right)} .
$$

Standardization is concluded by the total population at risk, by taking the assumption that every individual is similarly equally at risk of being infected or transmitted by pertussis. Hence, the relative risk of pertussis in every state of Malaysia is estimated by using this formula: 


$$
r_{i}=\theta_{i}=\frac{\left(\frac{O_{\mathrm{i}}}{N_{\mathrm{i}}}\right)}{\left(\frac{\sum O_{\mathrm{i}}}{\sum N_{j}}\right)} .
$$

\subsection{Descriptive Analysis}

Based on the data obtained from the Ministry of Health and the Department of Statistics Malaysia, the yearly pertussis cases in Malaysia are tabulated next.
It is evident from Table 1 that the number of pertussis cases had fluctuated from 2011 until 2018, with a few sharp rises $(2015,2018)$ and a dive (2016). However, throughout the duration of 8 years, 2018 had 888 cases, which is about 3.6 times the total cases (248) back in 2011, and more than doubled from the previous year 2017. To provide a better visual of the trend for each state in Malaysia, a time series graph is presented in Figure 1.

Table 1. Number of pertussis cases in Malaysia from 2011 to 2018

\begin{tabular}{|c|c|c|c|c|c|c|c|c|}
\hline Year & 2011 & 2012 & 2013 & 2014 & 2015 & 2016 & 2017 & 2018 \\
\hline Johor & 24 & 6 & 4 & 8 & 22 & 10 & 8 & 17 \\
\hline Kedah & 44 & 38 & 35 & 77 & 155 & 36 & 35 & 105 \\
\hline Kelantan & 24 & 16 & 12 & 15 & 30 & 19 & 13 & 73 \\
\hline Melaka & 29 & 5 & 6 & 22 & 33 & 8 & 8 & 31 \\
\hline Negeri Sembilan & 16 & 12 & 5 & 36 & 43 & 14 & 9 & 19 \\
\hline Pahang & 15 & 8 & 12 & 14 & 58 & 22 & 19 & 55 \\
\hline Perak & 9 & 7 & 8 & 17 & 41 & 12 & 8 & 36 \\
\hline Perlis & 3 & 10 & 8 & 18 & 31 & 6 & 7 & 10 \\
\hline Pulau Pinang & 6 & 8 & 6 & 4 & 11 & 9 & 10 & 27 \\
\hline Sabah & 13 & 8 & 9 & 20 & 22 & 27 & 79 & 107 \\
\hline Sarawak & 8 & 36 & 31 & 61 & 71 & 25 & 40 & 51 \\
\hline Selangor & 33 & 43 & 48 & 161 & 278 & 85 & 86 & 228 \\
\hline Terengganu & 23 & 20 & 29 & 32 & 103 & 12 & 10 & 75 \\
\hline W.P. Kuala Lumpur & 1 & 7 & 9 & 12 & 41 & 13 & 21 & 54 \\
\hline Malaysia & 248 & 224 & 222 & 497 & 939 & 298 & 353 & 888 \\
\hline
\end{tabular}

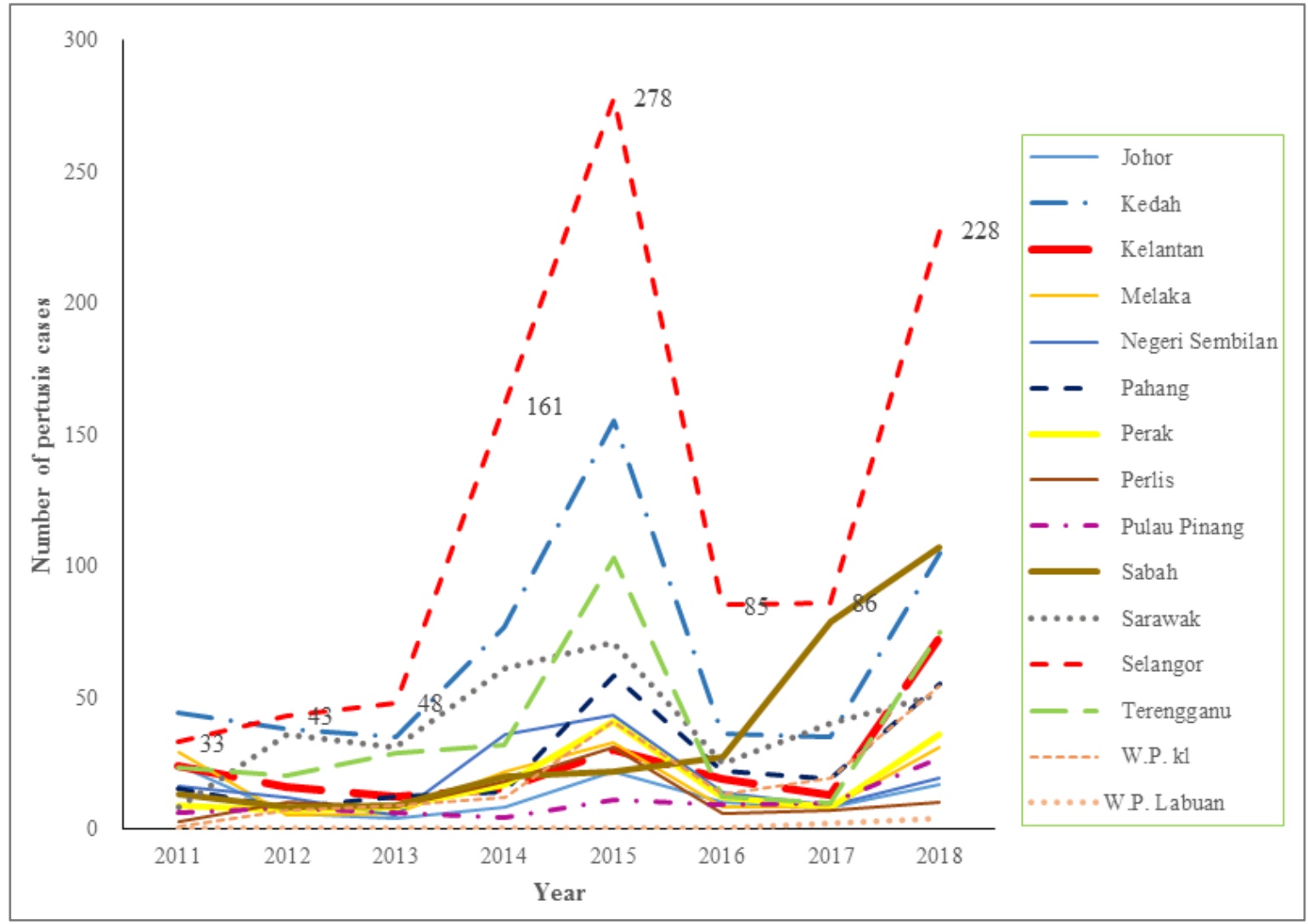

Figure 1. Number of pertussis cases by states in Malaysia 
Figure 1 illustrates the number of pertussis cases in all the 14 states. It is obvious that Selangor has the highest number of patients every year except for 2011 where Kedah tops all. From 2012 to 2016, Kedah remains the second-highest pertussis cases, declining numbers in 2016 and 2017, but rises sharply again in 2018. The overall trend for each state is similar, with the only steady changes observed from 2011 to 2013, followed by a dramatic rise from 2013 to 2015 and a plunge in 2016. The slight change from 2016 to 2017 is not sustained as another rapid increase is evident in 2018 for almost all the states.

\section{Results and Discussion}

Based on the data in Table 1 above, the results of the 2018 relative risk estimate for all states in Malaysia are shown in Table 2. Many states have a proportional risk of more than 1 , meaning that people within the state are more likely than people in the general population to get the disease. In other words, a marginal probability of less than 1 suggests that people in the area are less likely than people in the population to suffer from the disease.

Table 2 depicts the computed SMR values in descending order that is from the highest risk to the lowest risk. Terengganu has the highest SMR at 2.2059, suggesting that people in that state is about twice more susceptible of getting pertussis compared with people in Malaysia. It is to be noted that despite having the highest number of cases, Selangor is indeed in the $5^{\text {th }}$ place with
SMR of about 1.3. It can be seen from the five bottom rows that these 5 states have SMR less than 1, indicating that the people in the states are less likely to be infected with pertussis evaluated to other people in Malaysia.

Table 2. Relative risk estimation of pertussis disease for the year 2018

\begin{tabular}{cc}
\hline States & SMR \\
\hline Terengganu & 2.206 \\
Kedah & 1.750 \\
Kelantan & 1.431 \\
Perlis & 1.429 \\
Selangor & 1.281 \\
Melaka & 1.240 \\
Pahang & 1.196 \\
W.P. Kuala Lumpur \&Petaling Jaya & 1.038 \\
Sabah & 1.000 \\
Sarawak & 0.662 \\
Negeri Sembilan & 0.613 \\
Pulau Pinang & 0.551 \\
Perak & 0.522 \\
Johor & 0.165 \\
\hline
\end{tabular}

Using the above SMR values, a map is constructed to provide a visual illustration of high-risk to low-risk areas of pertussis occurrences for each state in Malaysia as portrayed in Figure 2. The highest intensity of colour represents very high-risk area based on relative risk. Every state is separated into five different levels of risks which are very low [0.165], low [0.165001-0.6623], medium [0.662301-1.0385], high [1.038501-1.4314] and very high [1.431401-2.2059].

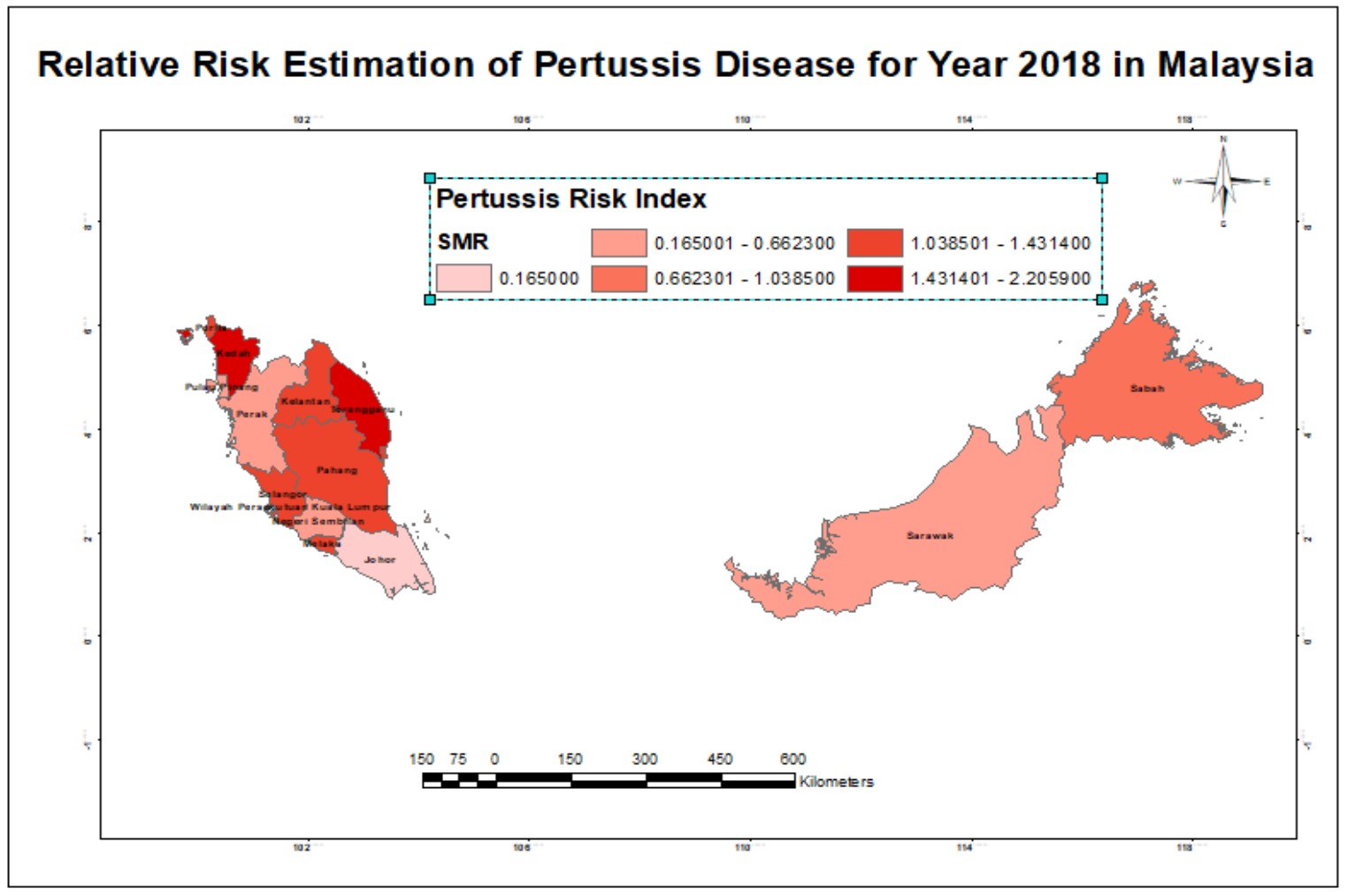

Figure 2. Disease map of pertussis disease in Malaysia for year 2018 
It is clearly evident from Figure 2 that Terengganu and Kedah are shaded in deep red, indicating very high risk areas for the pertussis disease. The states Kelantan, Pahang, Melaka, Selangor and Perlis are high-risk areas, while Sabah, W.P. Kuala Lumpur and Petaling Jaya fall in the medium-risk areas. The other four states are low-risk areas with the exception of Johor being a very low-risk area. It was reported [16] that Kedah and Terengganu have the highest number of residents who reject vaccination due to doubts about the vaccination status being "halal" or illegal and its contents being unsafe. This could be the reason for Kedah and Terengganu being the highest-risk area of the pertussis disease.

\section{Conclusions}

A disease map for pertussis in year 2018 is successfully constructed based on relative risk estimation using the popular SMR method. This study concludes that Terengganu and Kedah are the highest-risk areas while Johor is the lowest risk area for the pertussis disease. By considering the population size of the area instead of merely the number of cases, a more reliable information is generated in terms of the relative risk. This is an alternative statistic to be reported as it provides an insight into those areas which are more critical than others, such that the necessary actions to control and prevent pertussis can be prioritized accordingly. Additionally, the anti-vaccine movement needs to be curbed in order to protect the future leaders of our nation - our children. Despite the earlier attempt to make vaccination mandatory, the government has decided to make the public realize the importance and take the responsibility to vaccinate their children willingly. It is hopeful that a display of disease map clearly depicting the geographical area where someone resides, instead of numbers attached to the state name, would visually deliver the message better and psychologically have a meaningful impact in the long-run.

\section{Acknowledgement}

The authors would like to express gratitude and appreciation to Universiti Utara Malaysia and the Ministry of Higher Education for their support (LEADS Grant S/O Code: 12411).

\section{REFERENCES}

[1] Rusli, D. N. (26 April, 2012). Pertussis / Whooping Cough. Retrieved from My Health Portal - Ministry of Health: http://www.myhealth.gov.my/en/pertussis-whooping-coug $\mathrm{h} /$
[2] Whooping Cough. (9 December, 2019). Retrieved from Wikipedia The Free Encyclopedia: https://en.wikipedia.org / wiki/Whooping_cough

[3] Cunha, J. P. (13 August, 2019). Whooping Cough (Pertussis). (D. Perlstein, Editor) Retrieved from emedicalhealth: https://www.emedicinehealth.com/whoopi ng_cough_pertussis/article_em.htm\#what_is_the_prognosi s_for_whooping_cough

[4] Kuchar E, K.-S. M.-O. (2016). Pertussis: History of the Disease and Current Prevention Failure. National Center for Biotechnology Information.

[5] Centers for Disease Control and Prevention. (2019). Retrieved from Centers for Disease Control and Prevention : https://www.cdc.gov/pertussis/countries/index.html

[6] Gopal Krishnan, S., Fun, W. H., Ramadras, M. D., Yunus, R., Lye, Y. F., \& Sararaks, S. (2019). Pertussis clinical case definition: Time for change in developing countries?. PloS one, 14(7), e0219534. https://doi.org/10.1371/journal.pone. 0219534

[7] Arikiah, P. (14 April, 2019). Why childhood vaccination continues to be a divisive issue in Malaysia. Retrieved from CNA: https://www.channelnewsasia.com/news/asia/malay sia-childhood-vaccination-immunisation-debatable-113894 62

[8] Immunisation Programme in Malaysia. Vaccinology 2017III International Symposium for Asia Pacific Experts in Hanoi, Vietnam. 16-19 October 2017. Retrieved from https://www.fondation-merieux.org/wpcontent/uploads/20 17/10/ vaccinology-2017-faridah-kusnin.pdf

[9] Malaysian Healthcare Performance Unit, Malaysian Health at a Glance:2018, Ministry of Health Malaysia: Putrajaya.

[10] Samat, N. A. \& Percy, D. F. (2012). Dengue disease mapping in Malaysia based on stochastic SIR models in human populations. 2012 International Conference on Statistics in Science, Business and Engineering (ICSSBE), 623-627.

[11] Samat, N. A. \& Percy, D. F. (2012) Vector-borne infectious disease mapping with stochastic difference equations: an analysis of dengue disease in Malaysia, Journal of Applied Statistics, 39:9, 2029-2046, DOI: 10.1080/02664763.2012. 700450

[12] Michaels, I.H., Pirani, S.J., Carrascal, A. (2020). Visualizing 50 Years of Cancer Mortality Rates Across the US at Multiple Geographic Levels Using a Synchronized Map and Graph Animation. Prev Chronic Dis 2020;17:190286

[13] Musa et al. (2013). Use of GIS Mapping as a Public Health tool-From cholera to cancer. Health Services Insights 2013:6 111-116.

[14] Lawson, A. B., Browne, W. J., \& Rodeiro, C. L. (2003). Disease Mapping with WinBUGS and MLwiN. United States: Wiley; 1 edition.

[15] Everitt, Brian; Skrondal, Anders., (2010). Standardized Mortality Ratio (SMR). The Cambridge Dictionary of Statistics. New York: Cambridge University Press, pp. 409 
[16] Zainal, F. (04 March, 2019). "FAKTA: Kedah Negeri Paling Ramai Tolak Vaksin." Retrieved from Vitdaily: https://www.vitdaily.com/fakta-kedah-negeri-paling-ramai
-tolak-vaksin/?fbclid=IwAR1ysMQ3oS64YOEGxNOj-JnX BUnmzcHzXaa4lnn3iUe9Nz0c80_ev6Hd8Cg 